\title{
Palladium-Mediated C5 Substitution of Pyrimidine Nucleosides
}

One of the most efficient ways to link a reporter group to oligonucleotides is through the incorporation of a modified nucleoside during automated oligonucleotide synthesis. Most techniques, which make use of synthetic oligonucleotides, function by hybridization to a complementary sequence. In order to avoid interference with hybridization, reporter groups should ideally be attached so that they do not interfere with hybridization or destabilize dsDNA. Two different types of tethers are described here-a rigid amidopropynyl linker and a flexible aminoethylthioether linker. The rigid amidopropynyl tether, linked through C5 of deoxyuridine, is sufficiently long and positioned such that a reporter group attached at the distal end lies outside the major groove of a DNA duplex.

Basic Protocol 1 describes a detailed procedure for the synthesis of one example of deoxyuridine modified by an amidopropynyl-linked reporter group, 5-(3-nicotinamidopropyn-1-yl)-5'-O-(4,4'-dimethoxytrityl)-2'-deoxyuridine (Fig. 1.1.1). The procedure is general and may be applied to other amidopropynyl-linked functional groups. The nicotinoyl group was used only as an illustration of the strategy for incorporating a functional group on the amimopropynyl tether. For use in oligonucleotide synthesis, the C5-modified deoxyuridine is converted to a $3^{\prime}$-phosphoramite as described in UNIT 3.3.

Basic Protocol 2 outlines the synthesis of 5-(3-acetamido-1-thiapropyl)-2'-deoxyuridine (Fig. 1.1.2). In contrast to the amidopropynyl tether, the more conformationally flexible thioether tether was designed to allow positioning of a molecular tool (e.g., chemical cleavage reagent or cross-linking reagent) on a complementary nucleic acid by hybridization of the modified oligonucleotide. The thiapropyl linker is capable of bridging the

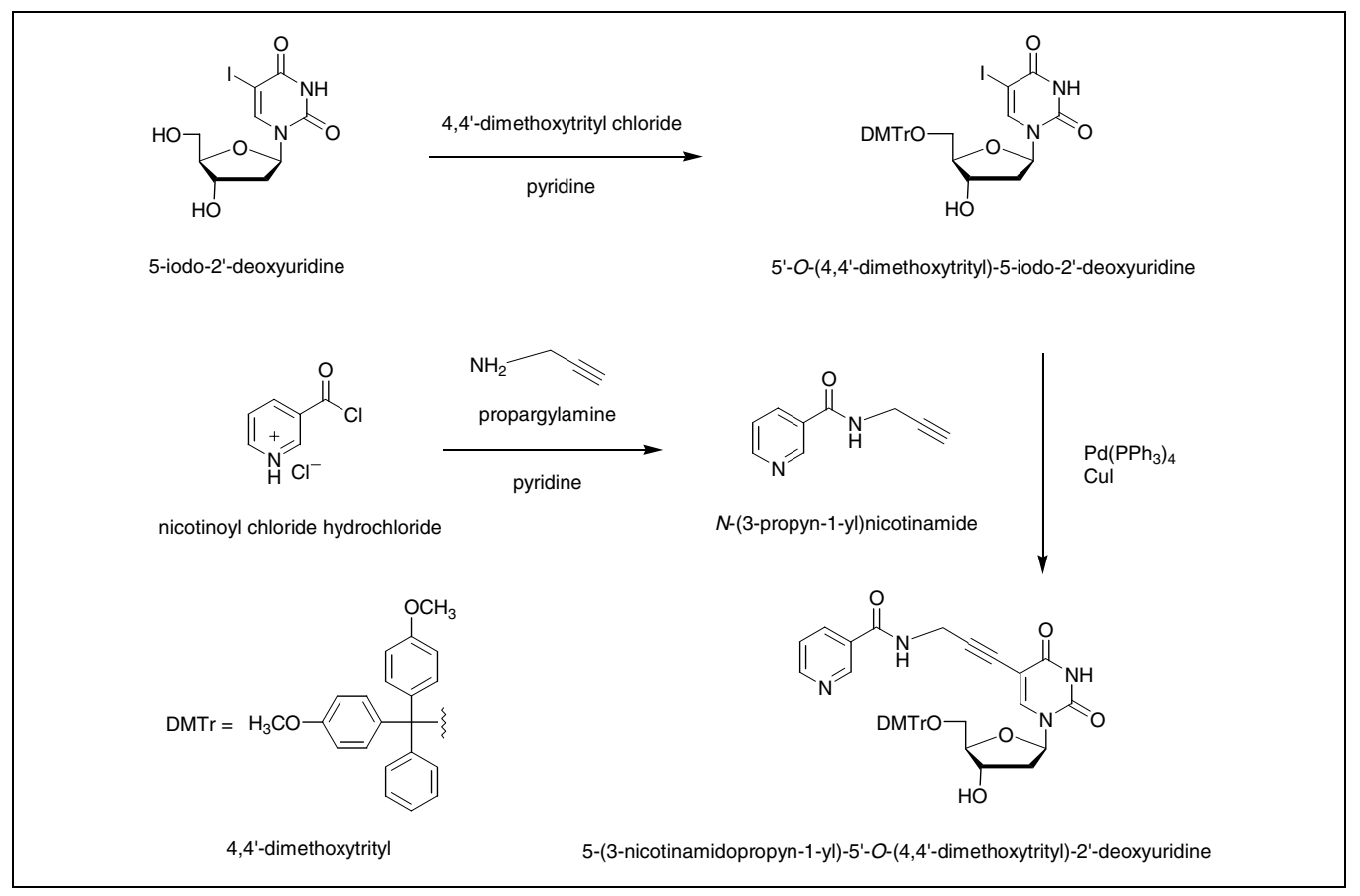

Figure 1.1.1 Synthetic scheme for the preparation of 5-(3-nicotinamidopropyn-1-yl)-5'-O-(4,4'-dimethoxytrityl)-2'-deoxyuridine from 5-iodo-2'-deoxyuridine. The structure of 4,4'-dimethoxytrityl (DMTr) is shown in the lower left. 
span between two helices. For use in oligodeoxyribonucleotide synthesis, the $\mathrm{N}$-acylated 5-(3-amino-1-thiapropyl)-2'-deoxyuridine is transformed to the 5'-dimethoxytrityl (DMTr) derivative as illustrated in Basic Protocol 1 for 5-iodo-2'-deoxyuridine, and is then converted to the $3^{\prime}$-phosphoramite as described in UNIT 3.3. Support Protocols 1 and 2 describe the preparation of two reagents needed for Basic Protocol $2-N, N^{\prime}$-bis(trifluoroacetyl)cystamine and $N$-acetoxysuccinimide, respectively.

BASIC PROTOCOL 1

PalladiumMediated C5 Substitution of Pyrimidine Nucleosides

\section{SYNTHESIS OF 5-(3-NICOTINAMIDOPROPYN-1-YL)-5'-O-(4,4'-} DIMETHOXYTRITYL)-2'-DEOXYURIDINE

The sequence of reactions outlined here (see Fig. 1.1.1) illustrate conditions that are useful for the synthesis of a wide variety of reporter groups linked through $\mathrm{C} 5$ of deoxyuridine. The protocol includes three steps: synthesis of the $\mathrm{N}$-acylated 3-aminopropyne (3-nicotinamidopropyne, in this example), reaction of 5-iodo-2'-deoxyuridine with 4,4'-dimethoxytrityl chloride, and palladium-catalyzed coupling of 3-nicotinamidopropyne with $5^{\prime}-O$-(4,4'-dimethoxytrityl)-5-iodo- $2^{\prime}$-deoxyuridine. For the introduction of a different reporter group, 3-aminopropyne can be $\mathrm{N}$-acylated by $\mathrm{RCOCl}$ (an acid chloride) or $\mathrm{RC}(\mathrm{O}) \mathrm{OC}(\mathrm{O}) \mathrm{R}$ (an anhydride) to obtain $\mathrm{RC}(\mathrm{O}) \mathrm{NHCH}_{2} \mathrm{C} \equiv \mathrm{CH}$, in which $\mathrm{R}$ is the desired reporter group.

CAUTION: All reactions should be run in a suitable fume hood to avoid inhalation of toxic vapors.

\section{Materials}

Nicotinoyl chloride hydrochloride

Pyridine, anhydrous

Nitrogen $\left(\mathrm{N}_{2}\right)$ stream

Triethylamine, freshly distilled (dried and purified by distillation at atmospheric pressure over calcium hydride; boiling point $=89^{\circ}$ to $90^{\circ} \mathrm{C}$ )

Propargylamine, reagent grade (typically $99 \%$ pure)

Dichloromethane, reagent grade

$10 \%(w / v)$ hydrochloric acid in water

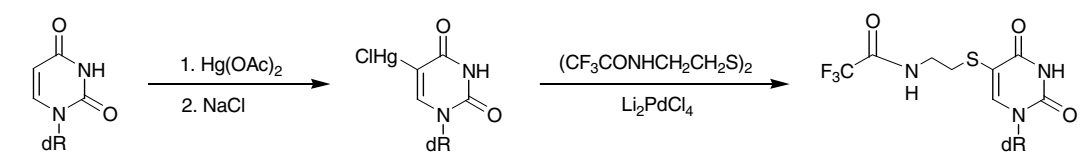

2'-deoxyuridine 5-chloromercurio-2'-deoxyuridine 5-[3-(trifluoroacetamido)-1-thiapropyl]-2'-deoxyuridine

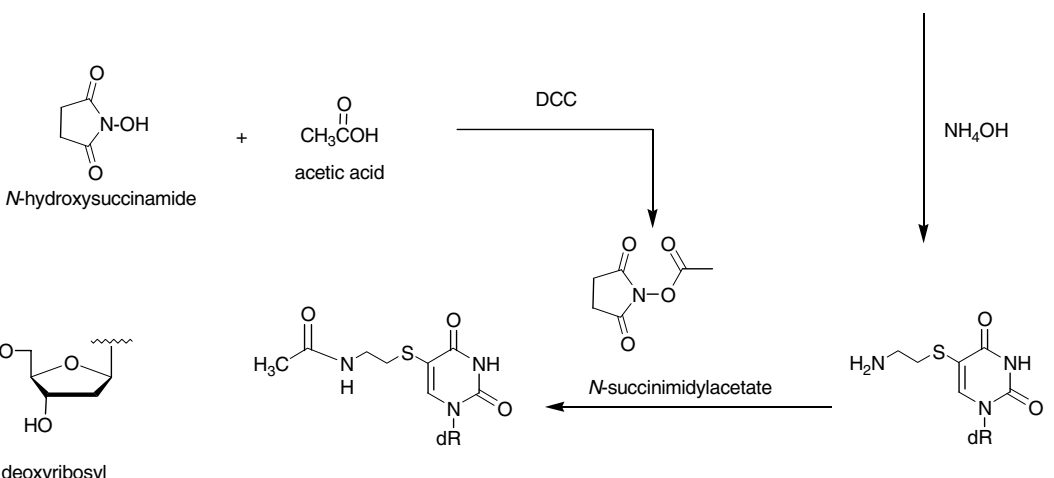

5-(3-acetamido-1-thiapropyl)-2'-deoxyuridine

5-(3-amino-1-thiapropyl)-2'-deoxyuridine

Figure 1.1.2 Synthetic scheme for the preparation of 5-(3-acetamido-1-thiapropyl)-2'-deoxyuridine from 2 -deoxyuridine. The structure of deoxyribosyl $(\mathrm{dR})$ is shown in the lower left. DCC, dicyclohexylcarbodiimide. 
Sodium sulfate, anhydrous

Silica gel (230 to 400 mesh)

Methanol, reagent grade

5-Iodo-2'-deoxyuridine

4,4'-Dimethoxytrityl chloride

Diethyl ether, anhydrous

$N, N$-Dimethylformamide, anhydrous

Argon gas (optional)

Tetrakis(triphenylphosphine)palladium, $\left[\left(\mathrm{C}_{6} \mathrm{H}_{5}\right)_{3} \mathrm{P}\right]_{4} \mathrm{Pd}$

Copper(I) iodide

$5 \%(\mathrm{w} / \mathrm{v}) \mathrm{Na}_{2}$ EDTA in water

Ethyl acetate, reagent grade

25- and 50-mL round-bottom flasks

Inert atmosphere/vacuum manifold (see Fig. 1.1.3)

$500-\mu \mathrm{L}$ and $1-\mathrm{mL}$ syringes with stainless steel needles

125- and 250-mL Ehrlenmeyer flask

$100-\mathrm{mL}$ separatory funnel

Filter funnel and Whatman no. 1 filter paper

Chromatotron and radial chromatography plate coated with silica gel (2-mm thickness; Harrison Research)

Rotary evaporator with vacuum pump and water aspirator

Glass column (2-cm i.d. $\times \geq 20$-cm length) with stopcock

Additional reagents and equipment for thin-layer chromatography (TLC; APPENDIX 4D)

\section{Synthesize N-(3-propyn-1-yl)nicotinamide}

1. In a dry $25-\mathrm{mL}$ round-bottom flask containing a $1 / 2$-in. magnetic stir bar, add 1.068 $\mathrm{g}$ nicotinoyl chloride hydrochloride $(6 \mathrm{mmol})$ to $10 \mathrm{~mL}$ of anhydrous pyridine under a nitrogen stream.

It is important that the flask be dry because nicotinoyl chloride reacts with water to give nicotinic acid. Glassware can be effectively dried by heating in a drying oven at $120^{\circ} \mathrm{C}$ for $2 \mathrm{hr}$. A small magnetic stir bar is generally dried at the same time as the flask and added to the flask prior to addition of the reagents.

A general setup for running small-scale reactions under a dry nitrogen atmosphere is shown in Figure 1.1.3. The apparatus is configured for air-sensitive palladium-catalyzed reactions. For most other reactions, it is not necessary to bubble nitrogen through the reaction mixture at inlet $(b)$.

2. Add $500 \mu \mathrm{L}$ triethylamine $(700 \mathrm{mg}, 7 \mathrm{mmol}$ ) with a $1-\mathrm{mL}$ syringe and stainless steel needle, and stir the mixture on a magnetic stirrer at room temperature until the triethylamine is completely in solution.

CAUTION: Wear reagent-impermeable protective gloves. Triethylamine and propargylamine are corrosive.

3. Add $250 \mu \mathrm{L}$ propargylamine $(365 \mathrm{mg}, 6.6 \mathrm{mmol}$ ) dropwise to the reaction mixture with a $500-\mu \mathrm{L}$ syringe and stainless steel needle, and continue stirring under nitrogen at room temperature for $4 \mathrm{hr}$.

4. Transfer contents of the flask to a $125-\mathrm{mL}$ Ehrlenmeyer flask containing $40 \mathrm{~mL}$ water. Stir the mixture briefly, transfer to a $100-\mathrm{mL}$ separatory funnel, and extract three times with $40 \mathrm{~mL}$ reagent-grade dichloromethane. 


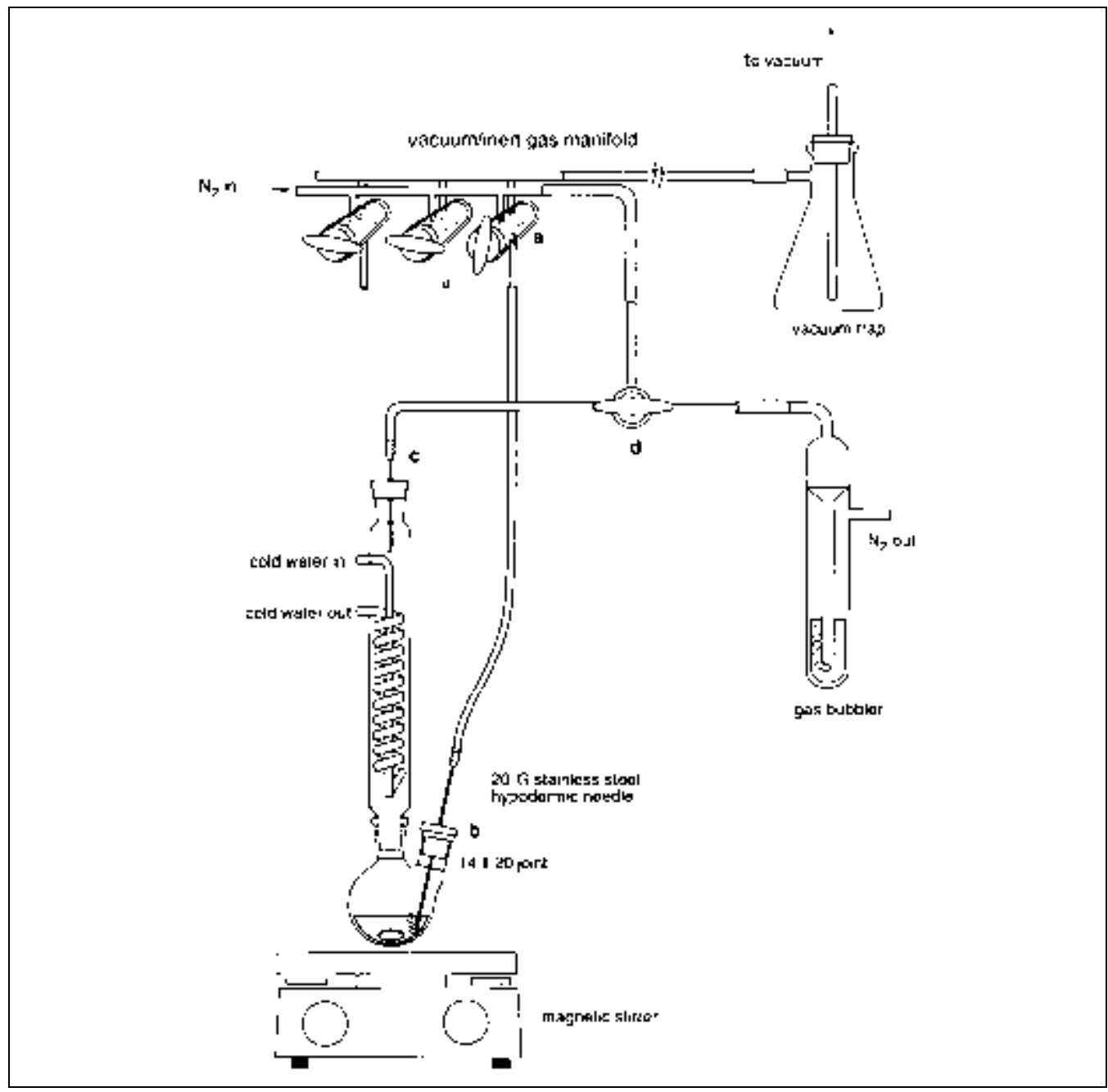

Figure 1.1.3 Inert atmosphere/vacuum manifold setup for running reactions in a dry, oxygen-free atmosphere. As shown, the inert gas can be introduced into the reaction flask through stopcock (a) and a hypodermic needle inserted at (b; 14/20 standard taper joint). The slow stream of inert gas then passes through stopcock (d) and out through the gas bubbler. Care must be taken to avoid completely closing the system while the insert gas is being introduced under pressure through the manifold. The setup requires a source of dry nitrogen. For very oxygen-sensitive reactions, the solution is purged by bubbling the inert gas (nitrogen or argon) directly through the solution by lowering the stainless steal hypodermic needle into the solution. The needle is then pulled up above the level of the solution and the flask and condenser evacuated through stopcock (a) with stopcock (d) positioned to allow only the inert gas to pass through to the gas bubbler.

5. Wash the combined organic extracts twice with $20 \mathrm{~mL}$ of $10 \%$ hydrochloric acid and then once with $10 \mathrm{~mL}$ water.

6. Transfer the combined dichloromethane solution to a 250-mL Erlenmeyer flask and add $0.5 \mathrm{~g}$ anhydrous sodium sulfate. Swirl the solution for a few minutes and then allow to stand for $30 \mathrm{~min}$.

7. Remove the drying agent by gravity filtration through a filter funnel fitted with Whatman no. 1 filter paper.

PalladiumMediated C5 Substitution of Pyrimidine Nucleosides

8. Wash the solid with $10 \mathrm{~mL}$ dichloromethane and remove solvent under reduced pressure using a rotary evaporator and water aspirator at room temperature to obtain the crude product. 
With a water aspirator and a water bath temperature of $25^{\circ} \mathrm{C}$, the dichloromethane can generally be completely removed within $30 \mathrm{~min}$. Longer periods of time may be required for complete removal of other higher-boiling-temperature solvents, such as methanol (step 9).

9. Purify the crude product by radial chromatography according to manufacturer's instructions using a chromatotron plate with 2-mm silica gel thickness. Elute with 96:4 (v/v) dichloromethane/methanol and collect the effluent in $\sim 10-\mathrm{mL}$ fractions.

The silica gel plates may be purchased from the manufacturer or prepared according to the manufacturer's instructions.

Alternatively, the crude product can be purified by column chromatography on silica gel (230 to 400 mesh; $12 \times 2 \mathrm{~cm}$ ) and eluted with the same solvent to give $\sim 10-\mathrm{mL}$ fractions.

10. Analyze fractions by thin-layer chromatrography (TLC) on silica gel. Develop TLC plates with 96:4 (v/v) dichloromethane/methanol.

11. Combine all fractions that contain the desired product $\left(R_{\mathrm{f}}=0.26\right)$. Evaporate the solvent under reduced pressure (see step 8) to obtain $N$-(3-propyn-1-yl)nicotinamide (784 mg, 78\%) as a white solid.

The compound is stable at room temperature and can be stored in a capped amber glass vial that has been purged with nitrogen. The authors do not generally store the product for $>1$ month, but it may be stable for a longer period of time. Unless otherwise specified, all intermediates synthesized as part of this protocol are stored under these conditions.

12. Analyze the product by mass spectrometry (MS) and by proton and carbon nuclear magnetic resonance (NMR) spectroscopy.

$N$-(3-Propyn-1-yl)nicotinamide has the following spectroscopic characteristics:

MS-EI $160\left(M^{+}\right), 106,78$

$M S-C I 161(M+H)^{+}$

${ }^{l} \mathrm{H} \mathrm{NMR} 250 \mathrm{MHz}\left(\mathrm{CHCl}_{3}-\mathrm{d}_{1}\right) \delta 9.0(\mathrm{~d}, \mathrm{~J}=1.6 \mathrm{~Hz}, \mathrm{H}-2$ aromatic, $1 \mathrm{H}), 8.74(\mathrm{~m}, \mathrm{H}-6, \mathrm{HH})$, $8.16(\mathrm{~m}, \mathrm{H}-5, \mathrm{lH}), 7.41(\mathrm{~m}, \mathrm{H}-4,1 \mathrm{H}), 6.79(\mathrm{br} \mathrm{s}, \mathrm{H}-\mathrm{N}, 1 \mathrm{H}), 4.28\left(\mathrm{dd}, \mathrm{J}_{1}=5.2 \mathrm{~Hz}, \mathrm{~J}_{2}=2.5\right.$ $\left.\mathrm{Hz}, \mathrm{N}-\mathrm{CH}_{2}-, 2 \mathrm{H}\right), 2.32(t, \mathrm{~J}=2.5 \mathrm{~Hz}, \mathrm{CCH}, \mathrm{lH})$

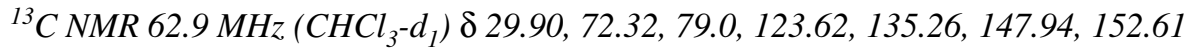

Analysis calculated for $\mathrm{C}_{9} \mathrm{H}_{8} \mathrm{~N}_{2} \mathrm{O}: \mathrm{C}, 67.5 ; \mathrm{H}, 5.0 ; \mathrm{N}, 17.5$; observed: $\mathrm{C}, 67.24 ; \mathrm{H}, 4.82$; $N, 17.65$. All values are given as percentages.

The same procedure may be used for the synthesis of other amide derivatives of propargylamine from carboxylic acid chlorides or anhydrides. The $R_{f}$ and the spectral characteristics will differ depending on the nature of the acyl group.

\section{Synthesize 5'-O-(4,4'-dimethoxytrityl)-5-iodo-2'-deoxyuridine}

13. In a $50-\mathrm{mL}$ round-bottom flask containing a $3 / 4$-in. egg-shaped magnetic stir bar, dissolve $354 \mathrm{mg}$ of 5-iodo-2'-deoxyuridine $(1 \mathrm{mmol})$ in $10 \mathrm{~mL}$ anhydrous pyridine.

CAUTION: The reaction must be performed in a well-vented fume hood.

This reaction is sensitive to water, and anhydrous solvent(s) must be used under inert atmosphere. Anhydrous pyridine obtained in Sure/Seal bottles (e.g., Aldrich) is suitable for use in this reaction without further drying. Otherwise, the pyridine should be dried over solid $\mathrm{KOH}$ and distilled over Linde type $5 \AA$ molecular sieves and solid $\mathrm{KOH}$. Pyridine has a fairly high boiling point $\left(115^{\circ} \mathrm{C}\right)$.

14. Evaporate approximately half the solvent using a rotary evaporator connected to a vacuum pump.

Synthesis of Modified Nucleosides 
It is advisable to use a vacuum pump rather than a water aspirator in order to rapidly evaporate the pyridine. This procedure removes water from the reaction mixture that may have been associated with the nucleoside by way of a pyridine-water azeotrope. With a good vacuum $(<1 \mathrm{mmHg})$ it is possible to concentrate the reaction mixture in 10 to $30 \mathrm{~min}$.

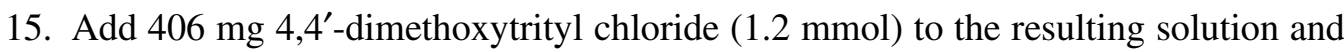
stir the mixture overnight at room temperature under a dry nitrogen atmosphere (Figure 1.1.3).

In this case it is not necessary to bubble nitrogen through the reaction mixture. The apparatus shown in Figure 1.1.3 provides a means to keep the reaction mixture dry.

4,4'-Dimethoxytrityl chloride may deteriorate if stored for long periods of time. The reagent should be light orange in color; do not use if it appears red. Although the reaction with 5-iodo-2'-deoxyuridine is allowed to run overnight, with pure reagents the reaction is typically compete within 1 to $2 \mathrm{hr}$.

16. Add $15 \mathrm{~mL}$ ice-cold water to the reaction mixture and then extract twice with $20 \mathrm{~mL}$ dichloromethane.

17. Combine the two organic extracts, wash with $10 \mathrm{~mL}$ water, and dry over anhydrous sodium sulfate (step 6).

18. Remove the drying agent, wash, and remove solvent as described (steps 7 and 8).

19. Dissolve the residue in $\sim 0.5 \mathrm{~mL}$ dichloromethane, introduce the resulting solution to a $10 \times 2-\mathrm{cm}$ column of 230- to 400-mesh silica gel, and elute with 98:2 (v/v) dichloromethane/methanol.

20. Collect the effluent in $\sim 10-\mathrm{mL}$ fractions and analyze by TLC on silica gel. Develop the plates with 98:2 (v/v) dichloromethane/methanol.

21. Combine fractions that contain the desired product $\left(R_{\mathrm{f}}=0.36\right)$ and evaporate the solvent under reduced pressure (step 8).

22. Add $2 \mathrm{~mL}$ anhydrous diethyl ether to the residue and evaporate under vacuum (step 8). Repeat this step until a white foam (646 mg, 98.5\% yield) is obtained.

It is important to continue the evaporation until a foam is obtained. Otherwise, the product will contain unacceptable amounts of solvents that may interfere with the subsequent reaction. This can generally be accomplished by using a rotary evaporator connected to a water aspirator, with the flask partially immersed in a room temperature water bath. The product may be stored under dry nitrogen in an amber bottle in the dark for a few weeks.

23. Analyze the product by mass spectrometry and by proton and carbon NMR spectroscopy.

5'-O-(4,4'-Dimethoxytrityl)-5-iodo-2'-deoxyuridine has the following spectroscopic characteristics:

${ }^{1} \mathrm{H} \mathrm{NMR} 250 \mathrm{MHz}\left(\mathrm{CHCl}_{3}-\mathrm{d}_{1}\right) \delta 8.38\left(\mathrm{~s}, \mathrm{~N}_{3}-\mathrm{H}, \mathrm{lH}\right), 8.13(\mathrm{~s}, \mathrm{H}-6, \mathrm{lH}), 7.46$ to $7.23(\mathrm{~m}$, DMTr aromatic protons, $9 H), 6.85(d, J=8.8 \mathrm{~Hz}, D M T r$ aromatic protons, $4 \mathrm{H}), 6.30$ (dd, $\left.J_{1}=7.6 \mathrm{~Hz}, \mathrm{~J}_{2}=5.5 \mathrm{~Hz}, \mathrm{H}-\mathrm{l}^{\prime}, 1 \mathrm{H}\right), 4.54\left(\mathrm{~m}, \mathrm{H}-\mathrm{3}^{\prime}, 1 \mathrm{H}\right), 4.08\left(\mathrm{~m}, \mathrm{H}-4^{\prime}, 1 \mathrm{H}\right), 3.80\left(\mathrm{~s}, \mathrm{OCH}_{3}\right.$, $6 \mathrm{H}$ ), $3.40\left(\mathrm{~m}, \mathrm{H}-5^{\prime}, 2 \mathrm{H}\right), 2.33$ and 2.44 (two sets of multiplets, $\mathrm{H}_{-} \mathrm{2}^{\prime}, 2 \mathrm{H}$ ), 1.98 (br s, $3^{\prime}-\mathrm{OH}$, $1 H)$

PalladiumMediated C5 Substitution of Pyrimidine Nucleosides
${ }^{13} \mathrm{C} \mathrm{NMR} \mathrm{62.9} \mathrm{MHz}\left(\mathrm{CHCl}_{3}-d_{1}\right) \delta 159.83,158.66,149.7,144.26,135.39,135.28,130.08$, $128.11,128.01,127.10,123.80,113.37,87.06,86.45,85.55,72.46,68.51,63.41,55.27$, 41.46

MS-PD m/z calculated for $\mathrm{C}_{30} \mathrm{H}_{29} \mathrm{IN}_{2} \mathrm{O}_{7}: 656$; observed: $656\left(\mathrm{M}^{+}\right)$. 
The same procedure may be applied to other $C 5$-substituted deoxyuridine derivatives such as 5-(3-acetamido-1-thiapropyl)-2'-deoxyuridine or 5-(3-trifluoroacetamido-1-thiapropyl)-2'-deoxyuridine (see Basic Protocol 2). The $R_{f}$ and spectral characteristics will differ depending on the nature of the C5 substituent.

\section{Synthesize 5-(3-nicotinamidopropyn-1-yl)-5'-0-(4,4'-dimethoxytrityl)-2'-deoxy- uridine}

24. In a two-neck $25-\mathrm{mL}$ round-bottom flask containing a $1 / 2$-in. magnetic stir bar (see Fig. 1.1.3), dissolve $328 \mathrm{mg}$ of $5^{\prime}$ - $O$-(4,4'-dimethoxytrityl)-5-iodo- $2^{\prime}$-deoxyuridine $(0.5 \mathrm{mmol}$; step 22$)$ in $4 \mathrm{~mL}$ anhydrous $N, N$-dimethylformamide.

Anhydrous N,N-dimethylformamide obtained in Sure/Seal bottles (Aldrich) may be used without further drying. Alternatively, $N, N$-dimethylformamide may be dried by distillation at reduced pressure (boiling point $=76^{\circ} \mathrm{C}$ at $39 \mathrm{mmHg}$ ) over Linde type $4 \AA$ molecular sieves.

25. Remove any dissolved oxygen in the solution by alternating three times between a vacuum and inert gas (dry nitrogen or argon) in the reaction apparatus.

As shown in Figure 1.1.3, the inert gas can be introduced directly to the solution through a tube attached at stopcock (a) and a hypodermic needle inserted at (b). When pulling a vacuum through stopcock (a), the needle must be lifted above the solution in the flask.

The subsequent coupling reaction proceeds by way of a zero-valent palladium complex. Although the dry reagents may be weighed out in the atmosphere, the reaction is very sensitive to oxygen once the reagents are in solution. A complex mixture of products may result if all oxygen is not removed from the system at this point.

26. Add the following reagents in the order indicated and then stir the reaction mixture at room temperature under nitrogen for $8 \mathrm{hr}$.

$300 \mu \mathrm{L}$ freshly distilled triethylamine $(218 \mathrm{mg}, 2.15 \mathrm{mmol})$

$240 \mathrm{mg} N$-(3-propyn-1-yl)nicotinamide (1.5 mmol; step 10)

$58 \mathrm{mg}$ tetrakis(triphenylphosphine)palladium (0.05 mmol)

$19 \mathrm{mg}$ copper(I) iodide $(0.1 \mathrm{mmol})$.

Experience with many different alkyne-coupling reactions has shown that it is not always possible to predict which palladium reagent will work most effectively. In some cases (e.g., with 3,3-dimethoxypropyne), bis(triphenylphosphine)palladium dichloride is more effective.

27. Add $10 \mathrm{~mL}$ of $5 \% \mathrm{Na}_{2}$ EDTA to the reaction mixture and extract twice with $30 \mathrm{~mL}$ dichloromethane.

28. Combine extracts and wash with $10 \mathrm{~mL}$ water. Dry the organic solution over anhydrous sodium sulfate (step 6).

29. Remove sodium sulfate by filtration (step 7), wash, and evaporate the solvent (step 8) to obtain the crude product as a foamy solid.

30. Purify the crude product by radial chromatography as in step 9, but elute with 50:50:5 (v/v/v) ethyl acetate/dichloromethane/methanol.

Alternatively, the crude product can be purified by column chromatography on silica gel $(230$ to 400 mesh; $10 \times 2 \mathrm{~cm})$ and eluted with 99:1 (v/v) dichloromethane/methanol.

31. Analyze fractions by TLC on silica gel. Develop TLC plates with 99:1 (v/v) dichloromethane/methanol. 
32. Combine all fractions that contain the desired product $\left(R_{\mathrm{f}}=0.39\right)$. Evaporate the solvent under reduced pressure (step 8).

33. Add $2 \mathrm{~mL}$ diethyl ether to the residue and evaporate under vacuum (step 8). Repeat this step until a white foam ( $215 \mathrm{mg}, 62.5 \%$ yield) is obtained.

The product may be stored a short period of time (a few weeks) under nitrogen in an amber bottle. Normally, it is converted immediately to the phosphoramidite for incorporation into an oligonucleotide.

34. Analyze the product by mass spectrometry and by proton and carbon NMR spectroscopy.

5'-O-(4,4'-Dimethoxytrityl)-5-(3-nicotinamidopropyn-1-yl)-2'-deoxyuridine has the following spectroscopic characteristics:

${ }^{1} \mathrm{H} \mathrm{NMR} 500 \mathrm{MHz}\left(\mathrm{CHCl}_{3}-\mathrm{d}_{1}\right) \delta 12.84\left(\mathrm{~s}, \mathrm{~N}_{3}-\mathrm{H}, \mathrm{lH}\right) 8.90(\mathrm{~d}, \mathrm{~J}=1.5, \mathrm{H}$-2 pyridine ring, $1 \mathrm{H}$ ), $8.68\left(\mathrm{dd}, \mathrm{J}_{1}=4.5 \mathrm{~Hz}, \mathrm{~J}_{2}=2 \mathrm{~Hz}, \mathrm{H}-4\right.$ pyridine moiety, $\left.1 \mathrm{H}\right), 8.22(\mathrm{~s}, \mathrm{H}-6$ pyrimidine moiety, $1 \mathrm{H}$ ), 7.90 (m, H-6 pyridine moiety, $1 \mathrm{H}$ ), $7.65(\mathrm{~s}, \mathrm{NH}-\mathrm{CO}-, 1 \mathrm{H}), 7.47$ to 7.17 (several sets, $m$, DMTr aromatic protons overlapped with $\mathrm{H}-5$ pyridine ring, $10 \mathrm{H}), 6.80(d, \mathrm{~J}=7$ $\mathrm{Hz}$, DMTr aromatic protons, $4 \mathrm{H}), 6.14\left(\mathrm{t}, \mathrm{J}=10 \mathrm{~Hz}, \mathrm{H}-\mathrm{l}^{\prime}, \mathrm{lH}\right), 4.59\left(\mathrm{~m}, \mathrm{H}-3^{\prime}, 1 \mathrm{H}\right), 4.18$ $\left(\mathrm{m},-\mathrm{CH}_{2} \mathrm{~N}\right.$ - and $\left.\mathrm{H}-4^{\prime}, 3 \mathrm{H}\right), 3.85\left(\mathrm{~s}, \mathrm{OCH}_{3}, 6 \mathrm{H}\right), 3.35\left(\mathrm{~m}, \mathrm{H}-5^{\prime}, 1 \mathrm{H}\right), 3.45\left(\mathrm{~m}, \mathrm{H}-5^{\prime \prime}, 1 \mathrm{H}\right)$, $2.56\left(m, H-2^{\prime}, 1 H\right), 2.32\left(m, H-2^{\prime \prime}, 1 H\right)$

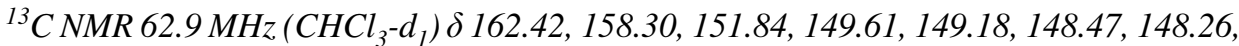
$142.75,135.58,135.40,135.19,134.80,129.79,129.50,127.72,126.66,123.33,123.23$, $122.94,122.54,113.05,86.70,65.61,70.83,63.42,54.95,41.69,30.32$

MS-CI m/z calculated for $\mathrm{C}_{39} \mathrm{H}_{36} \mathrm{~N}_{4} \mathrm{O}_{8}$ : 688; observed: $689(\mathrm{M}+\mathrm{H})^{+}$

MS-PD m/z observed: $688.8(M)^{+}, 303(D M T r)^{+}$

Analysis calculated for $\mathrm{C}_{39} \mathrm{H}_{36} \mathrm{~N}_{4} \mathrm{O}_{8}: \mathrm{C}, 68.01 ; \mathrm{H}, 5.21 ; \mathrm{N}, 8.13$; observed: $\mathrm{C}, 67.72 ; \mathrm{H}$, $5.26 ; \mathrm{N}, 8.31$. All values are given as percentage.

Other alkynes will give 5-substituted 2'-deoxyuridine products with different $R_{f}$ values and spectral characteristics.

BASIC PROTOCOL 2

PalladiumMediated C5 Substitution of Pyrimidine Nucleosides

\section{SYNTHESIS OF 5-(3-ACETAMIDO-1-THIAPROPYL)-2'-DEOXYURIDINE}

This protocol describes synthesis of 5-(3-acetamido-1-thiapropyl)-2'-deoxyuridine. The sequence of reactions outlined here (Fig. 1.1.2) illustrates conditions useful for the synthesis of different functional groups linked through an aminothiapropyl tether to C5 of deoxyuridine. The protocol includes four steps: preparation of 5-chloromercurio- 2 deoxyuridine, palladium-mediated coupling with $N, N^{\prime}$-bis(trifluoroacetyl)cystamine, removal of the trifluoroacetyl protecting group by ammonia, and coupling of an active ester to the pendant amino group. The latter reaction is illustrated with the active ester $\mathrm{N}$-acetoxysuccinimide. Other active esters may be used to link modifying groups to the aminothiapropyl tether. For example, a modified nucleoside that has a bipyridine ligand linked to the amino group of 5-(3-amino-1-thiapropyl)-2'-deoxyuridine was synthesized via an active ester of 4-carboxy-4'-methylbipyridine. This modified nucleotide was used to prepare oligonucleotides that function as metal-mediated sequence-specific nucleases (Bergstrom and Chen, 1996).

CAUTION: Mercuric acetate and organomercury compounds are highly toxic. Wear gloves and properly dispose of all waste materials generated by this procedure.

\section{Materials}

$2^{\prime}$-Deoxyuridine

Mercury(II) acetate 
$30 \%(\mathrm{w} / \mathrm{v})$ and $0.1 \mathrm{M}$ sodium chloride (reagent grade) in water

Ethanol, anhydrous

Diethyl ether, anhydrous

$N, N^{\prime}$-Bis(trifluoroacetyl)cystamine (see Support Protocol 1)

$0.1 \mathrm{M} \mathrm{Li}_{2} \mathrm{PdCl}_{4}$ solution (see recipe)

Hydrogen sulfide $\left(\mathrm{H}_{2} \mathrm{~S}\right)$

Methanol, reagent grade

Chloroform, reagent grade

Silica gel (230 to 400 mesh)

Concentrated ammonium hydroxide

Dry ice/acetone (for freezing)

$\mathrm{N}$-Acetoxysuccinimide (see Support Protocol 2)

Triethylamine, freshly distilled (dried and purified by distillation at atmospheric pressure over calcium hydride; boiling point $=89^{\circ}$ to $90^{\circ} \mathrm{C}$ )

Tetrahydrofuran, anhydrous

Ethyl acetate, reagent grade

100- and 200-mL round-bottom flasks

Temperature-controlled magnetic stirrer

Mortar and pestle

Whatman no. 1 filter paper

100-mm-diameter porcelain Buchner funnel

Rotary evaporator with water aspirator

Glass chromatography column (2-cm i.d. $\times \geq 20$-cm length) with stopcock

Lyophilizer

\section{Synthesize 5-chloromercurio-2'-deoxyuridine}

1. Dissolve $7.094 \mathrm{~g}$ of $2^{\prime}$-deoxyuridine $(31.09 \mathrm{mmol})$ in $30 \mathrm{~mL}$ water in a $200-\mathrm{mL}$ round-bottom flask and add a 1-in. magnetic stir bar.

2. Dissolve $10.449 \mathrm{~g}$ mercury(II) acetate $(32.8 \mathrm{mmol})$ in $45 \mathrm{~mL}$ water and add to the deoxyuridine.

3. Add $25 \mathrm{~mL}$ water and stir on a magnetic stirrer at $50^{\circ} \mathrm{C}$ for $2 \mathrm{hr}$.

During the course of the reaction, a dense white suspension of acetoxymercuriodeoxyuridine is formed. This is converted to the chloromercurio derivative in step 4.

4. While stirring, cool the reaction to $40^{\circ} \mathrm{C}$ and add $15 \mathrm{~mL}$ of $30 \%$ sodium chloride (4.5 $\mathrm{g}, 0.077$ moles).

5. Cool the reaction mixture to room temperature and filter the solution using a 100-mm-diameter porcelain Buckner funnel and Whatman no. 1 filter paper.

6. Wash the fine white precipitate sequentially with $60 \mathrm{~mL}$ of $0.1 \mathrm{M} \mathrm{NaCl}, 40 \mathrm{~mL}$ water, $20 \mathrm{~mL}$ ethanol, and $30 \mathrm{~mL}$ anhydrous diethyl ether.

7. Dry the white precipitate in a vacuum oven under vacuum at $80^{\circ} \mathrm{C}$ to obtain 5-chloromercurio- $2^{\prime}$-deoxyuridine $\left(13.95 \mathrm{~g} ; 97 \%\right.$ yield; melting point $=210.5^{\circ}$ to $\left.211^{\circ} \mathrm{C}\right)$.

5-Chloromercurio-2'-deoxyuridine is neither water nor air sensitive. It has been successfully stored without decomposition in amber bottles at room temperature for $>5$ years.

8. Analyze the product by IR, UV, and ${ }^{1} \mathrm{H}$ NMR spectroscopy.

5-Chloromercurio-2'-deoxyuridine has the following spectroscopic characteristics:

Synthesis of Modified Nucleosides 
${ }^{1} \mathrm{HNMR}\left(1.0 \mathrm{M} \mathrm{KCN} / \mathrm{D}_{2} \mathrm{O}\right) \delta 7.70(\mathrm{~s}, 1 \mathrm{H}), 6.35(\mathrm{t}, 1 \mathrm{H}, \mathrm{J}=6.5 \mathrm{~Hz}), 4.47(\mathrm{~m}, 1 \mathrm{H}), 3.99(\mathrm{~m}$, $1 \mathrm{H}), 3.83(\mathrm{~m}, 2 \mathrm{H}), 2.36(2 \mathrm{H}, d d, \mathrm{~J}=6 \mathrm{~Hz})$

$\operatorname{IR}(\mathrm{KBr}) 3365,1714,1642,1440,1275,1089,1040 \mathrm{~cm}^{-1}$

$U V(p H ~ 1.0) \lambda_{\max } 266(\varepsilon=10,440), \lambda_{\min } 239(\varepsilon=4,180) ;\left(p H\right.$ 9.0) $\lambda_{\max } 266(\varepsilon=10,120)$,

$\lambda_{\text {min }} 242(\varepsilon=5,440) ;(p H 12.3) \lambda_{\max } 267(\varepsilon=8,870), \lambda_{\min } 253(\varepsilon=7,070)$

Analysis calculated for $\mathrm{C}_{9} \mathrm{H}_{11} \mathrm{~N}_{2} \mathrm{O}_{5} \mathrm{HgCl}: \mathrm{C} 23.34 ; \mathrm{H}$ 2.39; $\mathrm{N}$ 6.05; observed: $\mathrm{C} 23.54 ; \mathrm{H}$ 2.32; $N$ 5.89.

\section{Synthesize 5-[3-(trifluoroacetamido)-1-thiapropyl]-2'-deoxyuridine}

9. Grind 5-chloromercurio-2'-deoxyuridine to a fine powder using a mortar and pestle.

CAUTION: In the process of grinding, the powder tends to accumulate static electricity and may be difficult to contain in the mortar and pestle. The mortar should be placed on a surface that can be easily cleaned. It is preferable to carry out this step in a hood to avoid breathing the powder. Grind $\geq 10 \%$ more material than required for the subsequent step to make up for loss that occurs during this process.

10. Place $0.926 \mathrm{~g}$ finely ground 5-chloromercurio- $2^{\prime}$-deoxyuridine $(2.0 \mathrm{mmol})$ and 1.720 g $N, N^{\prime}$-bis(trifluoroacetyl)cystamine $(5 \mathrm{mmol})$ in a $100-\mathrm{mL}$ round-bottom flask.

11. Add $40 \mathrm{~mL}$ of $0.1 \mathrm{M} \mathrm{Li}_{2} \mathrm{PdCl}_{4}$ solution to the flask and stir on a magnetic stir plate for $16 \mathrm{hr}$ at ambient temperature.

The mixture turns orange to yellow shortly after the reagents are combined, and usually yields a clear orange-yellow solution within a few hours.

12. Rapidly bubble hydrogen sulfide through the solution for $30 \mathrm{sec}$. Filter the mixture through a filter funnel by gravity filtration through Whatman no. 1 filter paper, and wash the solid with $20 \mathrm{~mL}$ reagent-grade methanol.

CAUTION: Hydrogen sulfide gas is highly toxic. All operations should be conducted in a well-ventilated fume hood. Hydrogen sulfide may be obtained in 1/2-lb (227-g) lecture bottles.

13. Using a rotary evaporator with a water aspirator, evaporate the solvent from the filtrate under reduced pressure to give an oil.

Because the methanol solution still contains hydrogen sulfide gas, this evaporation should be done using a rotary evaporator located inside a fume hood. Water aspirator pressure is normally sufficient to remove the methanol within 30 min at room temperature.

14. Purify the crude product on a $12 \times 2-\mathrm{cm}, 230$ - to 400 -mesh silica gel column, eluting with a linear chloroform/methanol gradient ranging from $10 \%$ to $18 \%$ methanol.

15. Combine fractions that contain material with $R_{\mathrm{f}}=0.30\left(\mathrm{CH}_{3} \mathrm{OH}-\mathrm{CHCl}_{3} 1: 9 \mathrm{v} / \mathrm{v}\right)$ or $R_{\mathrm{f}}=0.71\left(\mathrm{CH}_{3} \mathrm{OH}-\mathrm{CHCl}_{3} 1: 3 \mathrm{v} / \mathrm{v}\right)$, and evaporate the solvent on a rotary evaporator using a water aspirator to obtain 5-[3-(trifluoroacetamido)-1-thiapropyl]-2'-deoxyuridine $(0.41 \mathrm{~g} ; 51 \%$ yield $)$.

5-[3-(Trifluoroacetamido)-1-thiapropyl]-2'-deoxyuridine is neither water nor air sensitive. It can be stored without decomposition in amber bottles at room temperature for many years.

PalladiumMediated C5 Substitution of Pyrimidine Nucleosides

16. Analyze the product by MS and by IR, ${ }^{1} \mathrm{H}$, and ${ }^{13} \mathrm{C}$ NMR spectroscopy.

5-[3-(trifluoroacetamido)-1-thiapropyl]-2'-deoxyuridine has the following spectroscopic characteristics:

MS-FAB m/z calculated for $\mathrm{C}_{13} \mathrm{H}_{16} \mathrm{~F}_{3} \mathrm{~N}_{3} \mathrm{O}_{6} \mathrm{~S}$ : 399.071 ; observed: $400.079(\mathrm{M}+\mathrm{H})^{+}$ 
${ }^{1} \mathrm{H} \mathrm{NMR} 300 \mathrm{MHz}\left(\mathrm{CH}_{3} \mathrm{OH}-d_{4}\right) \delta 8.32(s, 1 \mathrm{H}, \mathrm{H}-6), 6.27\left(t, 1 \mathrm{H}, \mathrm{J}=6.6 \mathrm{~Hz}, \mathrm{H}-\mathrm{l}^{\prime}\right), 4.43$ ( $\left.m, 1 \mathrm{H}, \mathrm{H}-3^{\prime}\right), 3.95\left(\mathrm{~m}, \mathrm{lH}, \mathrm{H}-4^{\prime}\right), 3.79\left(\mathrm{~m}, 2 \mathrm{H}, \mathrm{H}-5^{\prime}\right), 3.47\left(\mathrm{t}, 2 \mathrm{H}, \mathrm{J}=6.0 \mathrm{~Hz}, \mathrm{H}-3^{\prime \prime}\right), 2.87$ ( $\left.m, 2 H, H-2^{\prime}\right), 2.32\left(t, 2 H, J=6.0 H z, H-2^{\prime \prime}\right)$

${ }^{13} \mathrm{C} \mathrm{NMR} 125 \mathrm{MHz}\left(\mathrm{CH}_{3} \mathrm{OH}-d_{4}\right) 164.5(\mathrm{C} 4), 159.0\left(q, \mathrm{~J}=286.6 \mathrm{~Hz}, \mathrm{C5}^{\prime \prime}\right), 106.8(\mathrm{C5})$, 89.0 (C1'), 86.8 (C4'), $72.0\left(C 3^{\prime}\right), 62.7\left(C 5^{\prime}\right), 41.4\left(C 2^{\prime}\right), 39.7\left(C 3^{\prime \prime}\right), 33.5\left(C 2^{\prime \prime}\right)$

$\operatorname{IR}(\mathrm{KBr}):$ 3550-2900 (br, O-H), 3423, $3443(\mathrm{~N}-\mathrm{H}), 1723,1692,1651(\mathrm{C}=\mathrm{O}), 1660,1553$, $1461(C=C), 1179,1271 \mathrm{~cm}^{-1}$

Analysis calculated for $\mathrm{C}_{13} \mathrm{H}_{16} \mathrm{~F}_{3} \mathrm{~N}_{3} \mathrm{O}_{6} \mathrm{~S}: \mathrm{C}, 39.08 ; \mathrm{H}, 4.01 ; \mathrm{N}, 10.52 ; \mathrm{S}, 8.03$; observed: C, 39.35; H, 3.63; N, 10.38; S, 8.22.

\section{Remove trifluoroacetyl protecting group}

17. In a $100-\mathrm{mL}$ round-bottom flask containing a 1-in. magnetic stir bar, dissolve 615 $\mathrm{mg}$ of 5-[3-(trifluoroacetamido)-1-thiapropyl]-2'-deoxyuridine $(1.5 \mathrm{mmol})$ in $10 \mathrm{~mL}$ methanol.

18. Add $30 \mathrm{~mL}$ concentrated ammonium hydroxide, cap the reaction container, and stir at room temperature for $16 \mathrm{hr}$.

19. Remove excess ammonia and methanol under reduced pressure using a rotary evaporator with a water aspirator. Freeze the remainder of the solution with a mixture of dry ice and acetone.

The methanol and ammonia can generally be removed on a rotary evaporator in $30 \mathrm{~min}$ or less at room temperature.

20. Remove water by lyophilization and dissolve the remaining solid in $3 \mathrm{~mL}$ anhydrous ethanol.

Synthesize 5-(3-acetamido-1-thiapropyl)-2'-deoxyuridine

21. Prepare a solution of $315 \mathrm{mg} N$-acetoxysuccinimide $(2 \mathrm{mmol}$ ) and $350 \mu \mathrm{L}$ freshly distilled triethylamine $(2.5 \mathrm{mmol})$ in $2 \mathrm{~mL}$ anhydrous tetrahydrofuran. Add to ethanolic solution and stir at room temperature for $4 \mathrm{hr}$.

Other active esters may be used in place of $N$-acetoxysuccinimide to place a different functional group on the tether. The resulting chromatographic characteristics and spectroscopic properties will change accordingly.

22. Remove the solvent under reduced pressure using a rotary evaporator and a water aspirator to obtain the crude product.

23. Purify the crude product by column chromatography using a $12 \times 2-\mathrm{cm}$ silica gel column, and eluting with a gradient of $100 \%$ ethyl acetate to $80: 20$ (v/v) ethyl acetate/methanol.

24. Collect effluent in $\sim 10-\mathrm{mL}$ fractions and analyze by TLC on silica gel, developing the plates with 85:15 (v/v) ethyl acetate/methanol.

25. Combine all fractions that contain the desired product $\left(R_{\mathrm{f}}=0.32\right)$. Evaporate the solvent under reduced pressure using a rotary evaporator and a water aspirator to obtain 5-[3-acetamido-1-thiapropyl]-2'-deoxyuridine (462 $\mathrm{mg}$; $87 \%$ yield) as a white solid.

The product may be stored indefinitely under nitrogen in an amber bottle.

26. Analyze the product by MS and by $\mathrm{UV},{ }^{1} \mathrm{H}$, and ${ }^{13} \mathrm{C}$ NMR spectroscopy.

5-(3-Acetamido-1-thiapropyl)-2'-deoxyuridine has the following spectroscopic characteristics:

Synthesis of Modified Nucleosides 
SUPPORT PROTOCOL 1

PalladiumMediated C5 Substitution of Pyrimidine Nucleosides
MS-FAB m/z calculated for $\mathrm{C}_{13} \mathrm{H}_{19} \mathrm{~N}_{3} \mathrm{O}_{6} \mathrm{~S}: 345.1073$; observed: $346.1072(\mathrm{M}+\mathrm{H})^{+}$

${ }^{1} \mathrm{H} \mathrm{NMR} 300 \mathrm{MHz}\left(\mathrm{CH}_{3} \mathrm{OH}-d_{4}\right) \delta 8.33(\mathrm{~s}, \mathrm{H}-6,1 \mathrm{H}), 6.25\left(t, \mathrm{~J}=7 \mathrm{~Hz}, \mathrm{H}-\mathrm{l}^{\prime}\right), 4.41\left(\mathrm{~m}, \mathrm{H}-3^{\prime}\right.$, lH), $3.93\left(\mathrm{~m}, \mathrm{H}-4^{\prime}, \mathrm{lH}\right), 3.78\left(\mathrm{~m}, \mathrm{H}-5^{\prime}, 2 \mathrm{H}\right), 3.31\left(\mathrm{~m}, \mathrm{SCH}_{2^{-}}, 2 \mathrm{H}\right), 2.78\left(\mathrm{t}, \mathrm{J}=6 \mathrm{~Hz},-\mathrm{CH}_{2} \mathrm{~N}-\right.$, $2 \mathrm{H}), 2.29\left(\mathrm{~m}, \mathrm{H}-2^{\prime}, 2 \mathrm{H}\right), 1.95$ ( $\mathrm{s}$, acetyl group's $\mathrm{CH}_{3}, 3 \mathrm{H}$ )

${ }^{13} \mathrm{C} \mathrm{NMR} 125 \mathrm{MHz}\left(\mathrm{DMSO}-d_{6}\right) 169.3,161.65,150.0,142.55,106.8,87.54,84.58,70.23$, 61.1, 39.94, 37.88, 32.1, 22.6

$U V$ (methanol) $\lambda_{\text {max }}: 282.4,202.0 \mathrm{~nm}$

Analysis calculated for $\mathrm{C}_{13} \mathrm{H}_{19} \mathrm{~N}_{3} \mathrm{O}_{6} \mathrm{~S}: \mathrm{C}, 45.2 ; \mathrm{H}, 5.5 ; \mathrm{N}, 12.2 ; \mathrm{S}$, 9.3; observed: $\mathrm{C}, 44.88$; $H, 5.37 ; \mathrm{N}, 12.27$; $S$, 9.32.

\section{SYNTHESIS OF $N, N^{\prime}$-BIS(TRIFLUOROACETYL)CYSTAMINE}

The trifluoroacetyl group has found wide application as a base-sensitive protecting group. It can be removed by ammonia under the same conditions used to deprotect oligodeoxyribonucleotides following synthesis by the phosphoramidite method. Amines are most commonly converted to trifluoracetyl derivatives by treatment with trifluoroacetic anhydride and a tertiary amine.

CAUTION: Both triethylamine and trifluoroacetic anhydride are corrosive. Wear gloves and work only in a suitable hood.

\section{Materials}

Chloroform, reagent grade

Cystamine dihydrochloride

Triethylamine, freshly distilled (dried and purified by distillation at atmospheric pressure over calcium hydride; boiling point $=89^{\circ}$ to $90^{\circ} \mathrm{C}$ )

Trifluoroacetic anhydride

$10 \%$ (w/v) $\mathrm{NaHCO}_{3}$

$2 \mathrm{~N} \mathrm{HCl}$

Sodium sulfate, anhydrous

Methanol, reagent grade

Ethyl acetate, reagent grade

Hexane, reagent grade

1-liter round-bottom flask

Drying tube containing Drierite

5-mL syringe

1-liter separatory funnel

Rotary evaporator with water aspirator

Vacuum oven at $35^{\circ} \mathrm{C}$

Buchner funnel and Whatman no. 1 filter paper

\section{Synthesize N,N'-bis(trifluoroacetyl)cystamine}

1. Filter reagent-grade chloroform through a short column of basic alumina and add 500 $\mathrm{mL}$ to a 1-liter round-bottom flask containing a magnetic stir bar and capped by a drying tube containing Drierite.

Reagent-grade chloroform typically contains ethanol to inhibit decomposition, which produces $\mathrm{HCl}$. The basic alumina removes the ethanol.

2. Add $9.0 \mathrm{~g}$ cystamine dihydrochloride $(40 \mathrm{mmol})$ and $20.2 \mathrm{~g}$ triethylamine $(27.8 \mathrm{~mL}$, $0.2 \mathrm{~mol}$ ) to the filtered chloroform. 
3. Cool the flask in a cold water bath $\left(0^{\circ}\right.$ to $\left.5^{\circ} \mathrm{C}\right)$ while slowly adding $1.5 \mathrm{~mL}$ trifluoroacetic anhydride $(18.5 \mathrm{~g}, 88 \mathrm{mmol})$ with a $5-\mathrm{mL}$ syringe.

Trifluoroacetic anhydride, which hydrolyzes to trifluoroacetic acid when exposed to water, should be stored in a hood and protected from moisture.

4. Stir the reaction mixture at room temperature overnight.

5. Transfer the reaction mixture to a 1-liter separatory funnel and wash sequentially with $250 \mathrm{~mL}$ water, $10 \% \mathrm{NaHCO}_{3}, 2 \mathrm{~N} \mathrm{HCl}$, and water again.

6. Dry the chloroform solution over anhydrous sodium sulfate for $1 \mathrm{hr}$ (see Basic Protocol 1, step 6).

7. Add $30 \mathrm{~mL}$ reagent-grade methanol, filter to remove the solid sodium sulfate (see Basic Protocol 1, step 7), and evaporate the solvent on a rotary evaporator using a water aspirator to yield a light yellow paste.

8. Add $100 \mathrm{~mL}$ of $2 \mathrm{~N} \mathrm{HCl}$ to give a slurry of light yellow crystals, and stir for $20 \mathrm{~min}$ at room temperature.

9. Filter the slurry and wash the solid product with $100 \mathrm{~mL}$ of $2 \mathrm{~N} \mathrm{HCl}$ and then with $100 \mathrm{~mL}$ water.

10. Dry the solid product in a vacuum oven at $35^{\circ} \mathrm{C}$ overnight.

The product is of suitable purity for use in palladium coupling reactions. To obtain analytically pure product, recrystallize as described below. The product may be stored indefinitely in a closed bottle at room temperature.

\section{Recrystallize product}

11. Dissolve product in a minimum of hot methanol.

12. Slowly add ethyl acetate to the warm methanol solution and allow to cool.

On cooling to room temperature, a colorless crystalline product separates (melting point $=111^{\circ} \mathrm{C}$ ).

13. Collect crystals by vacuum filtration through a Buchner funnel using Whatman no. 1 filter paper.

14. Collect a second crop by adding hexane to the warmed methanol/ethyl acetate solution, and cooling and collecting crystals again.

The total yield of crystalline product is $10.8 \mathrm{~g}(84 \%)$. The product may be stored indefinitely in a closed bottle at room temperature.

\section{Analyze product}

15. Analyze the product by ${ }^{1} \mathrm{H}$ and ${ }^{13} \mathrm{C}$ NMR spectroscopy.

$$
\begin{aligned}
& { }^{1} \mathrm{H} \mathrm{NMR}\left(250 \mathrm{MHz} \text {, acetone-d }{ }_{6}\right) \delta 2.70\left(t, \mathrm{CH}_{2} 4 \mathrm{H}, \mathrm{J}=10.4 \mathrm{~Hz}\right), 2.68\left(q, \mathrm{CH}_{2} 4 \mathrm{H}\right) \\
& { }^{13} \mathrm{C} \mathrm{NMR}\left(62.9 \mathrm{MHz} \text {, acetone }-d_{6}\right) \delta 37.2\left(\mathrm{CH}_{2}, \mathrm{~J}=10.4 \mathrm{~Hz}\right), 39.6\left(\mathrm{CH}_{2}\right), 117.0\left(\mathrm{CF}_{3}, \mathrm{~J}=\right. \\
& 287 \mathrm{~Hz}), 157.8(\mathrm{C}=\mathrm{O}) \text {. }
\end{aligned}
$$

\section{SYNTHESIS OF $N$-ACETOXYSUCCINIMIDE}

$\mathrm{N}$-Hydroxysuccinamide esters are generally prepared from carboxylic acids by reaction with dicyclohexylcarbodiimide and $N$-hydroxysuccinimide. The procedure outlined below can be applied to the synthesis of other $N$-hydroxysuccinimide esters. Active esters of some compound classes (e.g., amino acids) are commercially available. 


\section{Materials}

$\mathrm{N}$-Hydroxysuccinamide

Tetrahydrofuran, anhydrous

Nitrogen $\left(\mathrm{N}_{2}\right)$ gas

Glacial acetic acid

Dicyclohexylcarbodiimide (DCC)

Silica gel (optional; 230 to 400 mesh)

Ethyl acetate, reagent grade

Methanol, reagent grade

Vacuum manifold apparatus (Fig. 1.1.3) modified with a 10-mL conical flask and a $500-\mu \mathrm{L}$ syringe

Filter funnel and Whatman no. 1 filter paper

Glass chromatography column (optional; 2 -cm i.d. $\times 10$-cm length) with stopcock

1. In a $10-\mathrm{mL}$ conical flask containing a small magnetic stir bar, prepare a solution of $345.3 \mathrm{mg} N$-hydroxysuccinamide ( $3 \mathrm{mmol}$ ) in $1 \mathrm{~mL}$ anhydrous tetrahydrofuran under an inert atmosphere (e.g., nitrogen).

The setup shown in Figure 1.1.3 may be used with the inert gas inlet at (b) replaced by a $500-\mu L$ syringe containing glacial acetic acid (step 2 ). The apparatus is maintained under a positive pressure of nitrogen by the inlet line at (c).

2. Add $174 \mu \mathrm{L}$ glacial acetic acid ( $3 \mathrm{mmol})$.

3. Dissolve $620 \mathrm{mg}$ dicyclohexylcarbodiimide $(3 \mathrm{mmol})$ in $1 \mathrm{~mL}$ tetrahydrofuran and add to the reaction mixture. Stir the resulting solution at room temperature overnight (12 hr).

4. Remove the white precipitate (dicyclohexylurea) by filtration through Whatman no. 1 filter paper in a filter funnel.

5. Optional: Purify filtrate on a $10 \times 2-\mathrm{cm}$ silica gel column, eluting with $9: 1(\mathrm{v} / \mathrm{v})$ ethyl acetate/methanol. Collect appropriate fractions $\left(R_{\mathrm{f}}=0.45\right)$ and evaporate on a rotary evaporator using a water aspirator to give a white powder melting at $120^{\circ} \mathrm{C}$.

Although N-acetoxysuccinimide can be used without purification, it is generally preferable to purify if the product is to be stored. The product may be stored indefinitely under dry nitrogen in an amber bottle.

6. Analyze by MS and by proton NMR spectroscopy.

The purified product has the following spectroscopic characteristics:

$$
\begin{aligned}
& R_{f}=0.45\left(\mathrm{CH}_{2} \mathrm{Cl}_{2}, \text { silica }\right) \\
& { }^{1} \mathrm{H} \mathrm{NMR}\left(500 \mathrm{MHz}, \mathrm{CHCl}_{3}-\mathrm{d}_{1}\right) \delta 2.84\left(\mathrm{~s}, \mathrm{CH}_{2} 4 \mathrm{H}\right), 2.34\left(\mathrm{~s}, \mathrm{CH}_{3} 3 \mathrm{H}\right) \\
& M \mathrm{MS} \text {-CI calculated for } \mathrm{C}_{6} \mathrm{H}_{7} \mathrm{NO}_{4}: 157 \text {; observed } \mathrm{m} / \mathrm{z}: 158\left(\mathrm{M}+\mathrm{H}^{+} .\right.
\end{aligned}
$$

\section{REAGENTS AND SOLUTIONS}

Use deionized, distilled water in all recipes and protocol steps. For common stock solutions, see APPENDIX 2A; for suppliers, see SUPPLIERS APPENDIX.

PalladiumMediated C5 Substitution of Pyrimidine Nucleosides

\section{$0.1 \mathrm{M} \mathrm{Li}_{2} \mathrm{PdCl}_{4}$ solution}

$1.77 \mathrm{~g} \mathrm{PdCl}_{2}(0.01 \mathrm{~mol})$

$0.84 \mathrm{~g} \mathrm{LiCl}(0.02 \mathrm{~mol})$

$70 \mathrm{~mL}$ anhydrous methanol

Stir at room temperature for $24 \mathrm{hr}$ 
Adjust volume to $100 \mathrm{~mL}$ with methanol

The solution is generally not stored for more than a few weeks in a stoppered flask at room temperature.

\section{COMMENTARY}

\section{Background Information}

The C5 position of pyrimidine nucleosides is nearly ideal as a site for tethering molecular reporter groups and other molecular devices to oligodeoxyribonucleotides, as groups of different sizes may be attached without adversely affecting DNA duplex formation. In recent years, a variety of specialized probe moieties such as biotin (Langer et al., 1981; Shimkus et al., 1985; Cook et al., 1988), fluorophores (Prober et al., 1987; Tesler et al., 1989; Hagmar et al., 1995), paramagnetic probes (Spaltenstein et al., 1988, 1989; Kirchner et al., 1990), pendant catalytic moieties (Dreyer and Dervan, 1985; Bashkin et al., 1994; Kwiatkowski et al., 1994; Bergstrom and Chen, 1996; Shah et al., 1996), and cross-linkers (Gibson and Benkovic, 1987; Tabone et al., 1994; Chaudhuri and Kool, 1995; Meyer and Hanna, 1996) have been coupled to deoxyuridine and then incorporated into nucleic acids. The use of C5 linkers to functionalize nucleic acids has been reviewed (Goodchild, 1990). Although many kinds of linkers have been used to attach reporter groups to C5, alkynyl groups appear to be preferable because they enhance duplex stability (Sagi et al., 1993; Ahmadian et al., 1998).

Synthesis of 5-carboxamidopropynyl-2'deoxyuridine derivatives was initiated by $4,4^{\prime}-$ dimethoxytrityl protection of the readily available 5-iodo-2'-deoxyuridine following a standard procedure (Jones, 1984). Tritylation of 5 '-hydroxyl of 5-iodo-2'-deoxyuridine prior to the coupling reaction eliminated the need for toluyl protection and deprotection of the nucleoside hydroxyl groups (Robins and Barr, 1981, 1983). Palladium-mediated coupling reactions were carried out in dimethylformamide following a procedure similar to that reported by Hobbs (1989).

The steps outlined in the preparation of 5-(3-nicotinamidopropyn-1-yl)-5'-O-(4,4'-dimethoxytrityl)-2'-deoxyuridine provide a blueprint and strategy for the incorporation of many different kinds of reporter groups. As long as the desired reporter group has a reactive acyl functional group (carboxylic acid anhydride, chloride, or active ester), it is likely that it can be coupled to propargylamine and sub- sequently linked to deoxyuridine by the organopalladium coupling reaction.

The thioether-linked deoxyuridine derivative 5-[3-(trifluoroacetamido)-1-thiapropyl]2 -deoxyuridine was synthesized by the procedure reported by Bergstrom et al. (Bergstrom et al., 1991; Ahmadian et al., 1998) via a palladium-mediated reaction of the disulfide $N, N^{\prime}$ bis(trifluoroacetyl)cystamine with 5-chloromercurio- 2 '-deoxyuridine. Trifluoroacetyl functions as a base-sensitive protecting group that can be easily removed with aqueous ammonia. Because the trifluoroacetamido group is a poor ligand for palladium, it does not interfere with the palladium-mediated coupling reaction. Groups that are substantially more electron rich (such as acetamido) interfere with the coupling reaction. For this reason, the coupling reaction must be carried out prior to attaching electron-rich ligands to the cystamine amino group.

5-[3-(Trifluoroacetamido)-1-thiapropyl]-2'deoxyuridine may be incorporated into oligonucleotides as its $5^{\prime}$ - $O$-dimethoxytrityl-3'phosphoramidite derivative (procedure not given). The trifluoroacetyl protecting group is subsequently cleaved during the final ammonia deprotection of the oligonucleotide. This leaves the amino group available for conjugation to reporter groups or molecular tools at the oligonucleotide stage. Alternatively, 5-[3-(trifluoroacetamido)-1-thiapropyl]-2'-deoxyuridine may be deprotected and conjugated to the desired reporter groups or molecular tool prior to transformation to the $5^{\prime}$-O-dimethoxytrityl3 '-phosphoramidite derivative and incorporation into the oligonucleotide.

Synthesis of 5-[3-(trifluoroacetamido)-1thiapropyl]-2'-deoxyuridine requires 5-chloromercurio- $2^{\prime}$-deoxyuridine. This intermediate is obtained in high yield by direct electrophilic mercuration of 2'-deoxyuridine with mercuric acetate in aqueous solution (Bergstrom and Ruth, 1977). An important difference between the synthesis of the alkynyl-linked dU and the thioether-linked $\mathrm{dU}$ is that the former requires use of a protected dU and must be done with complete exclusion of oxygen, while the latter is not air sensitive and does not require protecting groups.
Synthesis of Modified Nucleosides

Current Protocols in Nucleic Acid Chemistry 
Table 1.1.1 Estimated Times for Completion of Syntheses

\begin{tabular}{lcl}
\hline Protocol & Time (hr) & Synthesis \\
\hline Basic Protocol 1 & 18 & N-(3-Propyn-1-yl)nicotinamide \\
& 20 & 5'-O-(4,4'-Dimethoxytrityl)-5-iodo-2'-deoxyuridine \\
& 15 & 5-(3-Nicotinamidopropyn-1-yl)-5'-O-(4,4'-dimethoxytrityl)- \\
& & 2'-deoxyuridine \\
Basic Protocol 2 & 16 & 5-Chloromercurio-2'-deoxyuridine \\
& 21 & 5-[3-(Trifluoroacetamido)-1-thiapropyl]-2'-deoxyuridine \\
Support Protocol 1 & 32 & 5-(3-Acetamido-1-thiapropyl)-2'-deoxyuridine \\
Support Protocol 2 & 36 & $N, N^{\prime}$-Bis(trifluoroacetyl)cystamine \\
\hline
\end{tabular}

There are alternative types of linkers as well as alternative methods for preparing alkynyl and thioalkyl linkers. In addition to the alkynyl and thioether linkages described here, alkyl and alkenyl linkers may also be obtained through organopalladium coupling methodology (Bergstrom and Ogawa, 1978). Examples of reporter groups linked through alkyl and alkenyl linkers are included in Literature Cited. The advantage of the alkynyl linker is the ease of preparation of the C5-substituted deoxyuridine that contains the $5^{\prime}$ protecting group (dimethoxytrityl) needed for subsequent oligonucleotide synthesis via the phosphoramidite methodology. In addition to the nicotinamidopropyne coupling reaction, the preparation of a series of other carboxamidopropynyl derivatives has been described (Ahmadian et al., 1998). Since organopalladium reactions can tolerate a wide variety of functional groups (e.g., hydroxyl, amido, carboxamide, ester, cyano, nitro, keto), there may be relatively few limitations on the nature of the group that can be introduced at $\mathrm{C} 5$ as a component of carboxamidopropyne. Deoxyuridine C5 substitution is preferred over deoxycytidine N4 or deoxyadenosine N6 substitution because the latter two modifications destabilize doublestranded DNA.

\section{Critical Parameters}

The most critical parameter in each reaction is the purity of the reactants and the reagents. Even fresh commercial reagents should be checked by TLC and ${ }^{1} \mathrm{H}$ NMR for purity and identity. 4,4'-Dimethoxytrityl chloride is sensitive to moisture and will deteriorate over time. The best results are obtained with a freshly opened bottle of the reagent. Alternatively, the authors store and transfer 4,4'-dimethoxytrityl chloride in a Vacuum Atmospheres dry box under a dry nitrogen atmosphere (any dry box should be suitable). The condensation reaction between $5^{\prime}$-O-(4,4'-dimethoxytrityl)-5-iodo$2^{\prime}$-deoxyuridine and the alkyne requires airsensitive tetrakis(triphenylphosphine)palladium. This reagent should also be stored and transferred under nitrogen or argon. Again, it is preferable to use freshly opened reagents, as they are supplied in sealed glass ampules that may be difficult to keep free of oxygen once opened.

When planning the construction of a C5modified nucleoside for introduction into oligonucleotides, the intermediates must not contain functional groups that are likely to interfere either with phosphoramidite preparation (e.g., hydroxyl) or oligonucleotide synthesis.

\section{Anticipated Results}

If the procedures are followed as described in this unit, the yields of isolated product should be comparable to that reported here. The palladium-catalyzed coupling reactions are especially sensitive to reagents and conditions. If an alkyne other than the one described in the protocol is used for the procedure, it may be necessary to try palladium catalysts other than tetrakis(triphenylphosophine)palladium. If the products are to be used to construct phosphoramidites for oligonucleotide synthesis, 50 $\mathrm{mg}$ of the C5-substituted 4,4'-dimethoxytrityl (DMTr) derivative is generally sufficient to obtain enough product to accomplish one coupling reaction on a $1-\mu \mathrm{mol}$ synthesis scale.

\section{Time Considerations}

The time required to complete each procedure is summarized in Table 1.1.1. The estimated times do not include the time necessary to purify solvents. In some cases, these may be purchased and used without further purification. 


\section{Literature Cited}

Ahmadian, M., Zhang, P., and Bergstrom, D.E. 1998. A comparative study of the thermal stability of oligodeoxyribonucleotides containing 5substituted-2'-deoxyuridines. Nucl. Acids Res. 26:3127-3135.

Bashkin, J.K., Sondhi, S.M., Sampath, U., d'Avignon, D.A., and Modak, A.S. 1994. Synthesis and connectivity assignment (by 2D-NMR) of a nucleoside-dipeptide: 5-[3-[[2-[[2-[[[2-Amino]1-oxo-3-[1H-imidazol-4-yl]propyl]amino]-1oxo-3-[1H-imidazol-4-yl]propyl]amino]ethyl] amino]-3-oxopropyl]-2'-deoxyuridine. New J. Chem. 18:305-318.

Bergstrom, D.E. and Chen, J. 1996. Sequence-specific oligodeoxyribonucletide cleavage by a major-groove-positioned metal-binding ligand tethered to C-5 of deoxyuridine. Bioorg. Med. Chem. Lett. 6:2211-2214.

Bergstrom, D.E. and Ogawa, M.K. 1978. C-5 substituted pyrimidine nucleosides. 2. Synthesis via olefin coupling to organopalladium intermediates derived from uridine and 2 -deoxyuridine. $J$. Am. Chem. Soc. 100:8106-8112.

Bergstrom, D.E. and Ruth, J.L. 1977. Preparation of C-5 mercurated pyrimidine nucleosides. J. Carbohydrates Nucleotides Nucleosides 42:257269.

Bergstrom, D.E., Beal, P., Jenson, J., and Lin, X. 1991. Palladium-mediated synthesis of C-5 pyrimidine nucleoside thioethers from disulfides and mercurinucleosides. J. Org. Chem. 56:5598-5602.

Chaudhuri, N.C. and Kool, E.T. 1995. Very high affinity DNA recognition by bicyclic and crosslinked oligonucleotides. J. Am. Chem. Soc. 117:10434-10442.

Cook, A.F., Vuocolo, E., and Brakel, C.L. 1988. Synthesis and hybridization of a series of biotinylated oligonucleotides. Nucl. Acids Res. 16:4077-4095.

Dreyer, G.B. and Dervan, P.B. 1985. Sequence-specific cleavage of single-stranded DNA: Oligodeoxynucleotide-EDTA.Fe(II). Proc. Natl. Acad. Sci. U.S.A. 82:968-972.

Gibson, K.J. and Benkovic, S.J. 1987. Synthesis and application of derivatizable oligonucleotides. Nucl. Acids Res. 15:6455-6467.

Goodchild, J. 1990. Conjugates of oligonucleotides and modified oligonucleotides: A review of their synthesis and properties. Bioconjugate Chem. 1:165-187.

Hagmar, P., Bailey, M., Tong, G., Haralambidis, J., Sawyer, W.H., and Davidson, B.E. 1995. Synthesis and characterization of fluorescent oligonucleotides. Effect of internal labelling on protein recognition. Biochim. Biophys. Acta 1244:259-268.

Hobbs, F.W. Jr. 1989. Palladium-catalyzed synthesis of alkynylamino nucleosides. A universal linker for nucleic acids. J. Org. Chem. 54:3420-3422.

Jones, R.A. 1984. Preparation of protected deoxyribonucleosides. In Oligonucleotide Synthesis: A Practical Approach (M.J. Gait, ed.) pp. 27-28. IRL Press, Washington, D.C.
Kirchner, J.J., Hustedt, E.J., Robinson, B.H., and Hopkins, P.B. 1990. DNA dynamics from a spin probe: Dependence of probe motion on tether length. Tetrahedron Lett. 31:593-596.

Kwiatkowski, M., Samiotaki, M., Lamminmaki, U., Mukkala, V.-M., and Landegren, U. 1994. Solidphase synthesis of chelate-labelled oligonucleoties: Application in triple-color ligase-mediated gene analysis. Nucl. Acids Res. 22:2604-2611.

Langer, P.R., Waldrop, A.A., and Ward, D.C. 1981. Enzymatic synthesis of biotin-labeled polynucleotides: Novel nucleic acid affinity probes. Proc. Natl. Acad. Sci. U.S.A. 78:66336637.

Meyer, K.L. and Hanna, M.M. 1996. Synthesis and characterization of a new 5-thiol-protected deoxyuridine for site-specific modification of DNA. Bioconjugate Chem. 7:401-412.

Prober, J.M., Trainor, G.L., Dam, R.J., Hobbs, F.W., Robertson, C.W., Zagursky, R.J., Cocuzza, A.J., Jensen, M.A., and Baumeister, K. 1987. A system for rapid DNA sequencing with fluorescent chain-terminating dideoxynucleotides. Science 238:336-341.

Robins, M.J. and Barr, P.J. 1981. Nucleic acid related compounds. 31. Smooth and efficient palladium-copper catalyzed coupling of terminal alkynes with 5-iodouracil nucleosides. Tetrahedron Lett. 22:421-424.

Robins, M.J. and Barr, P.J. 1983. Nucleic acid related compounds. 39. Efficient conversation of 5-iodo to 5-alkynyl and derived 5-substituted uracil bases and nucleosides. J. Org. Chem. 48:1854-1862.

Sagi, J., Szemzo, A., Ebinger, K., Szabolcs, A., Sagi, G., Ruff, E., and Otvos, L. 1993. Basemodified oligodeoxynucleotides. I. Effect of 5-alkyl, 5-(1-alkenyl) and 5-(1-alkynyl) substitution of the pyrimidines on duplex stability and hydrophobicity. Tetrahedron Lett. 34:2191-2194.

Shah, K., Neenhold, H., Wang, Z., and Rana, T.M. 1996. Incorporation of an artificial protease and nuclease at the HIV-1 Tat binding site of transactivation responsive RNA. Bioconjugate Chem. 7:283-289.

Shimkus, M., Levy, J., and Herman, T. 1985. A chemically cleavable biotinylated nucleotide: Usefulness in the recovery of protein-DNA complexes from avidin affinity columns. Proc. Natl. Acad. Sci. U.S.A. 82:2593-2597.

Spaltenstein, A., Robinson, B.H., and Hopkins, P.B. 1988. A rigid and nonperturbing probe for duplex DNA motion. J. Am. Chem. Soc. 110:12991301.

Spaltenstein, A., Robinson, B.H., and Hopkins, P.B. 1989. Sequence- and structure-dependent DNA base dynamics: Synthesis, structure, and dynamics of site and sequence specifically spin-labeled DNA. Biochemistry 28:9484-9495.
Synthesis of Modified Nucleosides 
Tabone, J.C., Stamm, M.R., Gamper, H.B., and Meyer, R.B. Jr. 1994. Factors influencing the extent and regiospecificity of cross-link formation between single-stranded DNA and reactive complementary oligodeoxynucleotides. Biochemistry 33:375-383.

Tesler, J., Cruickshank, K.A., Morrison, L.E., and Netzel, T. 1989. Synthesis and characterization of DNA oligomers and duplex containing covalently attached molecular labels: Comparison of biotin, fluorescin, and pyrene labels by thermodynamic and optical spectroscopic measurements. J. Am. Chem. Soc. 111:6966-6976.
Contributed by Mohammad Ahmadian Cerus Corp.

Concord, California

Douglas A. Klewer

Texas A\&M University

College Station, Texas

Donald E. Bergstrom

Purdue University

West Lafayette, Indiana
PalladiumMediated C5 Substitution of Pyrimidine Nucleosides 